\title{
First trimester uric acid level: a reliable marker for gestational diabetes mellitus
}

\author{
Suvarna Jyothi Ganta*, Sunanda R. Kulkarni
}

Department of Obstetrics and Gynecology, Chinmaya Mission Hospital, Bangalore, Karnataka, India

Received: 25 March 2019

Accepted: 06 May 2019

\section{*Correspondence:}

Dr. Suvarna Jyothi Ganta,

E-mail: suvarnajyothi0705@gmail.com

Copyright: () the author(s), publisher and licensee Medip Academy. This is an open-access article distributed under the terms of the Creative Commons Attribution Non-Commercial License, which permits unrestricted non-commercial use, distribution, and reproduction in any medium, provided the original work is properly cited.

\begin{abstract}
Background: The prevalence of diabetes mellitus (DM) is increasing worldwide and more in developing countries like India. The diabetic epidemic experienced in India can be due to strong genetic factors coupled with increasing urbanization, sedentary lifestyle, changes in the dietary patterns and increasing obesity. Indians are at an 11-fold increased risk of developing gestational glucose intolerance and hence universal screening is essential. Uric acid is a known marker of oxidative stress. Hyperuricemia in early pregnancy may be an indicator of the existing metabolic disturbance which can hinder the maternal physiological adaptations generally seen in pregnancy thus making the pregnant women more vulnerable to the development of gestational diabetes mellitus. The objective of this study was to investigate the association between elevated uric acid levels in the first trimester of pregnancy with gestational diabetes.

Methods: This prospective observational study was conducted in Chinmaya mission hospital, Bangalore from June 2016 to March 2017 (10 months). Three hundred and twelve (312) pregnant women of gestational age less than 12 weeks who attended the OBG outpatient department within this time of period for regular antenatal check-up were enrolled in the study. Along with the other antenatal investigations serum uric acid levels were estimated before 12 weeks and also between 24-28 weeks. At 24-28 weeks screening for GDM was done by OGCT using 75 gms of glucose (IADPISG criteria). Other parameters like age, parity, BMI, family history of diabetes was noted and compared.

Results: In our study, among the 312 pregnant women, 88 (28\%) developed GDM. Of these 74 Women (84\%) with GDM had uric acid levels above $3.5 \mathrm{mg} / \mathrm{dl}$ and 14 women $(15.9 \%)$ with GDM had uric acid levels below $3.5 \mathrm{mg} / \mathrm{dl}$. Women with higher BMI showed high uric acid levels.

Conclusions: Elevated serum uric acid in the first trimester has a significant correlation with development of GDM. In present study; the cut-off level of maternal serum uric acid of $3.5 \mathrm{mg} / \mathrm{dl}$ in the first trimester appears to have a good sensitivity and specificity in identifying those patients who are most likely to develop GDM later in pregnancy.
\end{abstract}

Keywords: Glucose challenge test, GDM, Hyperuricemia, Serum uric acid

\section{INTRODUCTION}

Gestational diabetes mellitus (GDM) is defined as carbohydrate intolerance of variable severity, with an onset or first recognition during pregnancy, whether insulin or only diet modification is used for treatment and whether or not the condition persists after pregnancy. ${ }^{1}$
Globally, prevalence of GDM is on the rise. In India, the prevalence of GDM was 2\% in 1982 followed by $7.62 \%$ in 1991 and $16.5 \%$ in 2003 with expected rate of 79.4 million in 2030 i.e. $15.1 \%$ increase from $2000 .^{2}$ Compared to European females, the South Asian especially Indian females have 11 fold increased risk for GDM. $^{3}$ 
GDM is important to be diagnosed early and treated effectively because of its implications in pregnancy. It is associated with various maternal complications like preeclampsia, preterm deliveries, polyhydramnios, still births, increased rates of LSCS and in fetus CNS, cardiac and genitourinary anomalies and NTD, macrosomia, still birth, birth injuries, hypoglycemic episodes post-delivery, hyperbilirubinemia and RDS. Also these women are at higher risk of developing DM in the next 2 decades as compared with the normal female population. Studies have shown that early glucose screening is definitely beneficial to patients to reduce the maternal and fetal morbidity. ${ }^{4}$

The earliest screening for GDM for a low risk pregnant woman is done only at 24-28 weeks. The prevalence of GDM in low risk population is about $7-10 \%$, any test which gives us an indicator of impending GDM will be of great help to advise the patient about life style and dietary modifications. Also early detection and treatment of morbidity will also ease the disease burden. ${ }^{5}$

Uric acid is the end product of purine metabolism and is synthesized by the enzyme xanthine oxidase. A large body of evidence suggests that uric acid could be an important risk factor for the development of diabetes in women. ${ }^{6}$ A study explored the relationship between beta cell function and uric acid. Insulin secretion was stimulated with L-arginine, and it was observed that the islet beta-cell function in hyperuricemic patients increases compensatively. Thus concluding that the serum uric acid level is positively correlated with insulin resistance.

In normal pregnancy, there is a decrease in the serum uric acid levels in the first trimester due to the increased GFR or reduced proximal tubular reabsorption. ${ }^{7}$

But as the pregnancy progresses the uric acid levels rise because of the increased fetal production, decreased clearance and decreased binding to albumin. ${ }^{8}$

High levels of uric acid in the early pregnancy may be an indicator of the existing metabolic disturbance which will hinder the maternal physiological adaptations generally seen in pregnancy and thus making the pregnant women more vulnerable to the development of gestational diabetes mellitus.

Early screening and accurate diagnosis of GDM is very important for timely intervention and optimal outcome both for the mother and the baby. This necessitates the search for a reliable indicator in the early gestation where we could educate the pregnant women about the impending complication and start the intervention early on. Hence this study was undertaken to investigate whether high uric acid level in the first trimester could be a predictor of GDM.

\section{METHODS}

The prospective observational study was conducted in Chinmaya mission hospital, Bangalore from June 2016 to march 2017. Pregnant women of gestational age less than 12 weeks who attended the OBG outpatient department within this time period for regular antenatal check-up were enrolled in the study with prior consent.

Demographic information, obstetrical, medical and family history was obtained. Height, weight, BMI was measured. Gestational age was calculated from the LMP and further confirmed by ultrasonography.

Blood samples were collected for estimation of serum uric acid along with other routine serological investigation. Serum uric acid level was assessed by enzymatic uricase method using Beckman Coulter AU480. At 24 to 28 weeks of gestation, one step test (DIPSI) to detect GDM using $75 \mathrm{~g}$ of oral glucose load was done irrespective of the last meal of the patient and blood sample was also collected for S. uric acid levels estimation.

Those antenatal mothers with plasma glucose level after 2 hours $>140 \mathrm{mg} / \mathrm{dl}$ were considered high risk and were subjected to oral glucose tolerance test (OGTT). Any changes in serum uric acid levels at 24 to 28 weeks were noted.

Ethical and scientific committee approval was obtained for the study.

\section{Inclusion criteria}

- Multiple pregnancies

- Chronic hypertension

- Presentational diabetes

- Gout

- Renal disease

- Smoking.

\section{Exclusion criteria}

- All patients who come for ante natal check up $(<12$ weeks).

\section{RESULTS}

Table 1: Age distribution of patients studied.

\begin{tabular}{|lll|}
\hline Age in years & No. of patients & $\%$ \\
\hline $19-24$ & 97 & 31.1 \\
\hline $25-29$ & 124 & 39.7 \\
\hline $30-34$ & 68 & 21.8 \\
\hline $35-39$ & 23 & 7.4 \\
\hline Total & 312 & 100.0 \\
\hline
\end{tabular}


In Table 1 , the mean age of the study population was 27 years.

Table 2 shows that Primigravidas constituted $55 \%$ and multigravidas constituted about $44 \%$ of our study population.

Table 2: Parity distribution of patients studied.

\begin{tabular}{|lll|}
\hline Parity & No. of patients & $\%$ \\
\hline Primi & 174 & 55.8 \\
\hline Multi & 138 & 44.2 \\
\hline Total & 312 & 100.0 \\
\hline
\end{tabular}

In Table 3 it shows that $152(48 \%)$ belonged to the normal BMI, 57 (18\%) were underweight, $86(27.6 \%)$ were overweight and $17(5.4 \%)$ belonged to the obese category in the study population.

Table 3: BMI $\left(\mathrm{kg} / \mathrm{m}^{2}\right)$ distribution of patients studied.

\begin{tabular}{|llll|}
\hline BMI $(\mathrm{kg} / \mathrm{m}$ & & No. of patients & $\%$ \\
\hline$<18.5$ & Underweight & 57 & 18.3 \\
\hline $18.5-24.9$ & Normal & 152 & 48.7 \\
\hline $25-29.9$ & Overweight & 86 & 27.6 \\
\hline$>30$ & Obese & 17 & 5.4 \\
\hline Total & & 312 & 100.0 \\
\hline
\end{tabular}

In Table 4, out of 312 women, 78 (25\%) had positive family history.

Table 4: Family history of diabetes mellitus.

\begin{tabular}{|lll|}
\hline Family history & Frequency & Percentage \\
\hline Present & 78 & $25 \%$ \\
\hline Absent & 234 & $75 \%$ \\
\hline Total & 312 & $100 \%$ \\
\hline
\end{tabular}

Table 5: Oral glucose challenge test distribution of patients studied.

\begin{tabular}{|c|c|c|}
\hline $\begin{array}{l}\text { Oral glucose } \\
\text { challenge test }\end{array}$ & $\begin{array}{l}\text { No. of } \\
\text { patients }\end{array}$ & Percentage \\
\hline Normal & 224 & 71.8 \\
\hline High (GDM) & 88 & 28.2 \\
\hline Total & 312 & 100.0 \\
\hline
\end{tabular}

According to Table 5, Out of 312 women, 88 (28.2\%) had high OGCT levels.

As per Table $6,76.5 \%$ of the obese women had high OGCT values. $80 \%$ of the women with normal BMI had low OGCT level. In our study, among 312 women, 88 women $(28 \%)$ developed GDM.

Table 6: Correlation of OCGT in relation to BMI of patients studied.

\begin{tabular}{|c|c|c|c|c|c|c|}
\hline \multirow[b]{2}{*}{ Variables } & \multicolumn{4}{|c|}{ BMI $\left(\mathrm{kg} / \mathrm{m}^{2}\right)$} & \multirow[b]{2}{*}{ Total $(\mathrm{n}=312)$} & \multirow[b]{2}{*}{$P$ value } \\
\hline & $\begin{array}{l}\text { underweight } \\
(\mathbf{n}=57)\end{array}$ & $\begin{array}{l}\text { normal } \\
(n=152)\end{array}$ & $\begin{array}{l}\text { overweight } \\
(n=86)\end{array}$ & $\begin{array}{l}\text { obese } \\
(n=17)\end{array}$ & & \\
\hline \multicolumn{7}{|c|}{ Oral glucose challenge test } \\
\hline Normal & $45(78.9 \%)$ & $122(80.3 \%)$ & $53(61.6 \%)$ & $4(23.5 \%)$ & $224(71.8 \%)$ & \multirow{2}{*}{$<0.001 * *$} \\
\hline High & $12(21.1 \%)$ & $30(19.7 \%)$ & $33(38.4 \%)$ & $13(76.5 \%)$ & $88(28.2 \%)$ & \\
\hline
\end{tabular}

Table 7: Uric acid in relation to BMI of patients studied.

\begin{tabular}{|lll|}
\hline BMI & Uric acid at 12 week & Uric acid at 24-28 weeks \\
\hline Underweight & $3.33 \pm 0.84$ & $3.16 \pm 0.83$ \\
\hline Normal & $3.38 \pm 1.03$ & $3.33 \pm 1.12$ \\
\hline Overweight & $3.84 \pm 1.15$ & $3.86 \pm 2.38$ \\
\hline obese & $5.09 \pm 0.83$ & $5.22 \pm 1.01$ \\
\hline Total & $3.59 \pm 1.10$ & $3.55 \pm 1.60$ \\
\hline P value & $<0.001 * *$ & $<0.001 * *$ \\
\hline
\end{tabular}

Table 8: Comparison of clinical variables in relation to OGCT.

\begin{tabular}{|lllll|}
\hline \multirow{2}{*}{ Variables } & \multicolumn{2}{l}{ Oral glucose challenge test } & Total & \multicolumn{2}{c|}{ P value } \\
\cline { 2 - 4 } & Normal & High & $3.59 \pm 1.10$ & $<0.001^{* *}$ \\
\hline Uric Acid at 12 weeks & $3.24 \pm 1.01$ & $4.48 \pm 0.76$ & $3.55 \pm 1.6$ & $<0.001^{* *}$ \\
\hline Uric Acid at 24 weeks & $3.17 \pm 1.67238$ & $4.51 \pm 0.8274$ & & \\
\hline
\end{tabular}

In Table 7, Overweight and obese women had high uric acid levels. And the mean uric acid level was $3.5 \mathrm{mg} / \mathrm{dl}$.
Women with BMI> 30 showed high uric acid levels. This shows development of GDM increases with increase in uric acid concentration. 
In Table 8 it shows, uric acid levels were high in women with high OGCT levels. The mean uric acid level is 3.5 which show good statistical significance.

According to Table, 9 age wise differences in serum uric acid was statistically significant $(\mathrm{p}<0.001)$.serum uric acid levels increased with increasing age.
Parity wise differences in serum uric acid at $<12$ weeks of gestational age was not statistically significant (p-0.175).

Overweight and obese and those with family history of diabetes had significantly $(\mathrm{P}<0.001)$ higher levels of serum uric acid at 12 weeks of gestation when compared to their counterparts.

Table 9: Association between serum uric acid at <12 weeks of gestation and various studied parameters.

\begin{tabular}{|c|c|c|c|c|c|}
\hline \multirow{2}{*}{ Variables } & & \multicolumn{2}{|c|}{ Uric acid at <12 weeks } & \multirow{2}{*}{ Total } & \multirow{2}{*}{ P value } \\
\hline & & $<3.5$ & $>3.5$ & & \\
\hline \multirow{5}{*}{ Age } & $19-24$ & $78(81 \%)$ & $19(18 \%)$ & 97 & \multirow{5}{*}{$<0.001$} \\
\hline & $25-29$ & $89(72.5 \%)$ & $35(27.5 \%)$ & 124 & \\
\hline & $30-34$ & $49(73.3 \%)$ & $19(26.7 \%)$ & 68 & \\
\hline & $35-39$ & $11(47.9 \%)$ & $12(52.10 \%)$ & 23 & \\
\hline & Total & $227(67.3 \%)$ & $85(32.7 \%)$ & 312 & \\
\hline \multirow{3}{*}{ Parity } & Primi & $126(71 \%)$ & $48(28.8 \%)$ & 174 & \multirow{3}{*}{0.175} \\
\hline & Multi & $89(63 \%)$ & $49(36.8 \%)$ & 138 & \\
\hline & Total & $215(67.3 \%)$ & $97(32.7 \%)$ & 312 & \\
\hline \multirow{5}{*}{ BMI } & Under weight & $47(84.3 \%)$ & $10(15.7 \%)$ & 57 & \multirow{5}{*}{$<0.001$} \\
\hline & Normal & $119(77.6 \%)$ & $33(22.4 \%)$ & 152 & \\
\hline & Overweight & $38(43.4 \%)$ & $48(56.6 \%)$ & 86 & \\
\hline & Obese & $1(8.3 \%)$ & $16(91.7 \%)$ & 17 & \\
\hline & Total & $205(67.3 \%)$ & $107(32.7 \%)$ & 312 & \\
\hline \multirow{3}{*}{ Family history } & Yes & $10(14.5 \%)$ & $68(85 \%)$ & 78 & \multirow{3}{*}{$<0.001$} \\
\hline & No & $210(67 \%)$ & $24(32 \%)$ & 234 & \\
\hline & Total & 220 & 92 & 312 & \\
\hline
\end{tabular}

\section{DISCUSSION}

Gestational diabetes mellitus is one of the common metabolic disorders in pregnancy with varying prevalence in India and worldwide which can be attributed to the genetic, cultural and socio-economic factors. GDM is important to be diagnosed early and treated effectively because of its implications both on the mother and fetus. Also these women are at higher risk of developing DM in the next 2 decades as compared with the normal female population. Studies have shown that early glucose screening is definitely beneficial to patients to reduce the maternal and fetal morbidity. ${ }^{5}$

The maternal age ranged from 19-39 years and the mean age of 27.46 years. Serum uric acid levels increased with increasing age similar results were found by Aparna et al and Nader et al. ${ }^{9,10}$

In the present study parity wise differences with serum uric acid was not statistically significant as the $p$ value was 0.175 , similar finding was noted in the study by Rasika et al. ${ }^{11} 48 \%$ of women belonged to the normal BMI, overweight and obese women had significantly higher levels of serum uric acid when compared to their counterparts. Similar finding was noted by Rasika et al. ${ }^{11}$
Majority of the subjects had no significant family history. Out of 312 women 78 (25\%) had positive family history, out of which $19.7 \%$ of women developed GDM showing a strong association. The same was stated by Ratnakaran et al. ${ }^{12}$

Mohamed Nabih El Gharib et al, potrayed that a cut off of uric acid $4 \mathrm{mg} / \mathrm{dl}$ is a strong predictor of GDM. ${ }^{13}$ Prospective cohort study done by Manish Chauhan used uric acid level $>5 \mathrm{mg} / \mathrm{dl}$ with $83.3 \%$ more chance of GDM. ${ }^{14}$ This study $(3.5 \mathrm{mg} / \mathrm{dl})$ can be well compared to Aparna et al, Singh U et al and Nader et al who used 3.4, $>5$ and 3.11 as the uric acid cut off level respectively. ${ }^{9,10,6}$

\section{CONCLUSION}

An elevated serum uric acid level in the first trimester has a significant correlation with development of GDM. Cut off level of $3.5 \mathrm{mg} / \mathrm{dl}$ appears to have a good sensitivity and specificity. Early interventions by dietary and exercise regimes in these patients can reduce the maternal and neonatal complications. It is our suggestion that serum uric acid level should be done as a routine test during the first antenatal visit itself as a reliable predictor for the development of GDM. 
Funding: No funding sources

Conflict of interest: None declared

Ethical approval: The study was approved by the Institutional Ethics Committee

\section{REFERENCES}

1. Romero American Diabetes Association. Gestational diabetes mellitus. Diabetes Care. 2014;37(Suppl 1):14-80.

2. Agarwal S, Gupta AN. Gestational Diabetes. J Assoc Physicians India. 1982;30:203-5.

3. Seshiah V, Balaji V, Balaji MS, Sanjeevi CB, Green A. Gestational diabetes mellitus in India. J Assoc Physicians India. 2004;52:707-11.

4. Nahum GG, Wilson SB, Stainslaw. Early pregnancy glucose screening for GDM. J Reprod Med. 2002;47(8):656-62.

5. Swami SR, Mehetre R, Shivane V, Bandgar TR, Menon PS, Shah NS. Prevalence of carbohydrate intolerance of varying degrees in pregnant females in western India. J Indian Med Assoc. 2008;106:712-4.

6. Singh U, Mehrotra S, Singh R, Sujata, Gangwar ML, Shukla B. Serum uric acid: A novel risk factor for GDM. Int J Med Res Rev. 2015;3(1):10-5.

7. Davison JM, Dunlop W. Renal hemodynamics and tubular function normal human pregnancy. Kidney Int. 1980;18:152-61.

8. Lind T, Godfrey KA, Otun H, Philips PR. Changes in serum uric acid concentrations during normal pregnancy. Br J Obstet Gynaecol. 1984;91:128-32.
9. Kappaganuthu A, Jyothisachan, Shailaja G. Hyperuricemia in early pregnancy: a marker for gestational diabetes mellitus. IOSR Journal Dent Med Sci. 2014;13(12):51-4.

10. Nader A, AboHassan, Rezk AY, Salama KM. Early detection of gestational diabetes via measurement of first trimester maternal serum uric acid. Med J Cairo Univ. 2016;84(2):151-8.

11. Rasika C, Samal S, Ghose S. Association of elevated first trimester serum uric acid levels with development of GDM. J Clin Diagno Res. 2014;8(12):OC01-OC05.

12. Ratnakaran R, Connelly PW, Sermer M, Zinman B, Hanley AJG. The impact of family history of diabetes on risk factors for gestational diabetes. Cln Endocrinol. 2007;67:754-60.

13. El-Gharib M, Mahfouz AE, Morad MA. Prediction of gestational diabetes by measuring first trimester maternal serum uric acid concentration. J Basic Clin Reproduct Sci.2013;2:27-31.

14. Rao CN, Uthraraj K. Elevated 1st trimester serum uric acid - a risk for gestational diabetes mellitus among South-Indians: a prospective observational, longitudinal study. Int J Reprod Contracept Obstet Gynecol. 2017;6:4923-7.

Cite this article as: Ganta SJ, Kulkarni SR. First trimester uric acid level: a reliable marker for gestational diabetes mellitus. Int J Reprod Contracept Obstet Gynecol 2019;8:2358-62. 